\title{
Esophageal Pressure Versus Gas Exchange to Set PEEP During Intraoperative Ventilation
}

\author{
Gianmaria Cammarota, Gianluigi Lauro, Ilaria Sguazzotti, Iolanda Mariano, Raffaella Perucca, \\ Antonio Messina, Marta Zanoni, Eugenio Garofalo, Andrea Bruni, Francesco Della Corte, \\ Paolo Navalesi, Elena Bignami, Rosanna Vaschetto, and Francesco Mojoli
}

\begin{abstract}
BACKGROUND: Pneumoperitoneum and Trendelenburg position affect respiratory system mechanics and oxygenation during elective pelvic robotic surgery. The primary aim of this randomized pilot study was to compare the effects of a conventional low tidal volume ventilation with PEEP guided by gas exchange $\left(V_{\text {Gas-guided }}\right)$ versus low tidal volume ventilation tailoring PEEP according to esophageal pressure $\left(V_{\text {Pes-guided }}\right)$ on oxygenation and respiratory mechanics during elective pelvic robotic surgery. METHODS: This study was conducted in a single-center tertiary hospital between September 2017 and January 2019. Forty-nine adult patients scheduled for elective pelvic robotic surgery were screened; 28 subjects completed the full analysis. Exclusion criteria were American Society of Anesthesiologists physical status $\geq 3$, contraindications to nasogastric catheter placement, and pregnancy. After dedicated naso/orogastric catheter insertion, subjects were randomly assigned to $V_{\text {Gas-guided }}\left(\mathrm{F}_{\mathrm{IO}_{2}}\right.$ and PEEP set to achieve $\left.\mathrm{S}_{\mathrm{pO}_{2}}>94 \%\right)$ or $\mathrm{V}_{\text {Pes-guided }}$ (PEEP tailored to equalize end-expiratory transpulmonary pressure). Oxygenation $\left(\mathrm{P}_{\mathrm{aO}} / \mathrm{F}_{\mathrm{IO}_{2}}\right)$ was evaluated (1) at randomization, after pneumoperitoneum and Trendelenburg application; (2) at $60 \mathrm{~min}$; (3) at $120 \mathrm{~min}$ following randomization; and (4) at end of surgery. Respiratory mechanics were assessed during the duration of the study. RESULTS: Compared to $V_{\text {Gas-guided, }}$ oxygenation was higher with $V_{\text {Pes-guided }}$ at 60 min (388 \pm 90 vs $308 \pm 95 \mathrm{~mm} \mathrm{Hg}, P=.02)$, at 120 min after randomization $(400 \pm 90$ vs $308 \pm 81 \mathrm{~mm}$ $\mathrm{Hg}, P=.008)$, and at the end of surgery $(402 \pm 95 \mathrm{vs} 312 \pm 95 \mathrm{~mm} \mathrm{Hg}, P=.009)$. Respiratory system elastance was lower with $V_{\text {Pes-guided }}$ compared to $V_{\text {Gas-guided }}$ at 20 min $(24.2 \pm 7.3$ vs $\left.33.4 \pm 10.7 \mathrm{~cm} \mathrm{H}_{2} \mathrm{O} / \mathrm{L}, P=.001\right)$ and $60 \mathrm{~min}\left(24.1 \pm 5.4 \mathrm{vs} 31.9 \pm 8.5 \mathrm{~cm} \mathrm{H}_{2} \mathrm{O} / \mathrm{L}, P=.006\right)$ from randomization. CONCLUSIONS: Oxygenation and respiratory system mechanics were improved when applying a ventilatory strategy tailoring PEEP to equalize expiratory transpulmonary pressure in subjects undergoing pelvic robotic surgery compared to a $\mathbf{V}_{\text {Gas-guided }}$ approach. (ClinicalTrials.gov registration NCT03153592). Key words: positive pressure respiration; pneumoperitoneum; respiratory mechanics; laparoscopy. [Respir Care 2020;65(5):625-635. (C) 2020 Daedalus Enterprises]
\end{abstract}

\section{Introduction}

The laparoscopic robotic technique has gained a leading role in elective pelvic surgery by minimizing the surgical

Drs Cammarota, Perucca, and Zanoni are affiliated with the Department of Anesthesiology and Intensive Care, Maggiore della Carità University Hospital, Novara, Italy. Drs Lauro, Sguazzotti, Mariano, Della Corte, and Vaschetto are affiliated with the Department of Translational Medicine, Eastern Piedmont University, Novara, Italy. Dr Messina is affiliated with the Department of Anesthesiology and Intensive Care, Humanitas Research Hospital, Milan, Italy. Drs Garofalo, Bruni, and approach and improving clinical outcome. ${ }^{1,2}$ Usually, Trendelenburg (head-down position) and carbon dioxide pneumoperitoneum are applied during robotic surgery to optimize the surgical field. ${ }^{3}$ However, the increased abdominal pressure associated with the Trendelenburg

Navalesi are affiliated with the Department of Medical and Surgical Science, Magna Graecia University, Catanzaro, Italy. Dr Bignami is affiliated with the Anesthesiology, Critical Care and Pain Medicine Division, Department of Medicine and Surgery. University of Parma, Parma, Italy. Dr Mojoli is affiliated with the Anesthesia and Intensive Care Department, Policlinico S. Matteo IRCCS Foundation, Pavia, Italy. 


\section{SETTING PEEP INTRAOPERATIVELY}

position impairs respiratory function, decreasing the lung volume below functional residual capacity and increasing the risk of atelectasis in dependent lung regions. ${ }^{3-5}$ These pathophysiologic changes amplify the risk of perioperative complications, such as hypoxemia, especially in obese patients. ${ }^{6,7}$ Furthermore, atelectasis worsens the stress and strain of alveolar structures, ${ }^{3,8}$ causing ventilator-induced lung injury. ${ }^{9}$ Preventing ventilator-induced lung injury during surgery improves perioperative outcome. . $^{10,11}$

Several different ventilatory strategies have been proposed to optimize both oxygenation and respiratory mechanics during laparoscopy. ${ }^{12-16}$ Application of PEEP increases functional residual capacity by reducing the cranial shift of the diaphragm during laparoscopic and robotic surgery. ${ }^{16,17}$ Moreover, a ventilatory strategy using lungrecruitment maneuvers followed by the application of PEEP is effective in improving respiratory mechanics and oxygenation during laparoscopy in normal-weight and obese subjects. ${ }^{12,14} \mathrm{~A}$ different approach to optimize ventilatory mechanics and oxygenation during laparoscopic surgery could use transpulmonary pressure, previously applied to manage ventilation during the course of ARDS. ${ }^{18}$ In this regard, a comparison between a conventional low tidal volume ventilation with PEEP set according to gas exchange $\left(\mathrm{V}_{\text {Gas-guided }}\right)$ versus a low tidal ventilatory strategy tailoring PEEP to equalize or positivize expiratory transpulmonary pressure through a calibrated esophageal pressure $\left(\mathrm{P}_{\mathrm{es}}\right)$ measurement $\left(\mathrm{V}_{\text {Pes-guided }}\right)$ has not been conducted yet. To our knowledge, when $\mathrm{P}_{\mathrm{es}}$-driven mechanical ventilation has been applied, no esophageal balloon calibration procedure has been employed during surgery, ${ }^{13}$ leading to inappropriate levels of PEEP or lung overdistention.

The primary aim of this pilot, prospective, randomized study was to observe the effects of $\mathrm{V}_{\text {Gas-guided }}$ and $\mathrm{V}_{\text {Pes-guided }}$ on intraoperative oxygenation, assessed after definitive pneumoperitoneum and Trendelenburg achievement, in subjects undergoing elective pelvic robotic surgery. Furthermore, any changes on intraoperative respiratory mechanics, rate of lung recruitment maneuvers, perioperative lung aeration ultrasound score, rate and type of

A version of this study was presented as at the SMART Congress, held May 9-11, 2018, in Milan, Italy, and at the 2018 ESICM Lives Congress, held October 20-24, 2018, in Paris, France.

Drs Cammarota and Lauro are co-first authors.

Dr Mojoli discloses relationships with Hamilton Medical and GE Healthcare. The other authors have no conflicts to disclose.

Correspondence: Gianmaria Cammarota $\mathrm{MD} \mathrm{PhD}$, Department of Anesthesiology and Intensive Care, Maggiore della Carità University Hospital, Corso Mazzini18, 28100 Novara, Italy. E-mail: gmcamma@gmail.com.

DOI: $10.4187 /$ respcare. 07238

\section{QUICK LOOK}

\section{Current knowledge}

Pneumoperitoneum and Trendelenburg position, usually utilized in pelvic robotic surgery, negatively affect respiratory mechanics with a consequent worsening of oxygenation. Moreover, the increase in driving pressure associated with the aforementioned changes puts patients at risk for ventilator-induced lung injury, a well-defined cause of poor outcomes.

\section{What this paper contributes to our knowledge}

Tailoring PEEP to avoid negative end-expiratory transpulmonary pressure led to oxygenation improvement in subjects undergoing elective pelvic robotic surgery. Indeed, this approach improved respiratory mechanics and reduced driving pressure, and preserved a better lung aeration in the early postoperative period.

perioperative complications, and length of hospital stay were analyzed as secondary end points.

\section{Methods}

\section{Subjects}

The protocol was designed in accordance with Helsinki Declaration principles and approved (CE 62/17) by the ethical committee of Maggiore della Carità University Hospital, in Novara, Italy. Written informed consent was obtained from all subjects, according to local regulations. This manuscript adheres to the applicable CONSORT guidelines. Adult subjects undergoing elective laparoscopic surgery for radical prostatectomy or hysterectomy were included. Exclusion criteria were American Society of Anesthesiologists physical status $\geq 3$, contraindications to nasogastric catheter placement, and pregnancy. This investigation was carried out in the Department of Anesthesiology and Intensive Care, Maggiore della Carità University Hospital, in Novara, Italy.

After subjects arrived in the operating room, a lung ultrasound assessment was performed to compute the lung ultrasound score using a $2-4 \mathrm{MHz}$ or a $7.5-12 \mathrm{MHz}$ probe (Mylab 30cv, Esaote spa, Milan, Italy) as previously proposed. ${ }^{19-21}$ Subsequently, midazolam $0.02 \mathrm{mg} / \mathrm{kg}$ was administered intravenously, and the standard intraoperative vital parameter monitoring was applied (ie, electrocardiogram, pulse oximeter, noninvasive blood pressure measurement). After anesthesia induction via intravenous propofol $2 \mathrm{~mL} / \mathrm{kg}$, remifentanil $0.15-0.3 \gamma / \mathrm{kg} / \mathrm{min}$, and rocuronium $0.6 \mathrm{mg} / \mathrm{kg}$, orotracheal intubation was assured and mechanical ventilation was started in volume control 


\section{SETTING PEEP INTRAOPERATIVELY}

mode with an inspiratory square flow. Tidal volume ranged from 6 to $8 \mathrm{~mL} / \mathrm{kg}$ ideal body weight, ${ }^{18} \mathrm{~F}_{\mathrm{IO}_{2}}$ was set to maintain $\mathrm{S}_{\mathrm{pO}_{2}}>94 \%$, and breathing frequency was set to achieve and maintain an end-tidal carbon dioxide concentration of $35-45 \mathrm{~mm} \mathrm{Hg}$. An inspiratory time, accounting for $33 \%$ of total mechanical respiratory time, was set while an inspiratory pause equal to $20 \%$ of inspiratory time was chosen. No PEEP was initially added. Inhalatory sevoflurane (1-2\%), intravenous remifentanil $0.1-0.15 \gamma / \mathrm{kg} / \mathrm{min}$, and extemporary rocuronium were administered according to the anesthesia maintenance plan. The radial artery was cannulated for continuous invasive blood pressure monitoring. Anesthesia depth was targeted to a bi-spectral index (Aspect A-2000; Aspect Medical System, Newton, Massachusetts) range of 40-60 throughout the surgery.

A gastric tube equipped with both esophageal and gastric balloons (Nutrivent Sidam, Mirandola, Italy) was advanced through the nose or mouth for $50-55 \mathrm{~cm}$ to reach the stomach, where the balloons were inflated to the recommended volume (ie, $4 \mathrm{~mL}$ ). Before insertion, balloons were both deflated and secured with a 3-way stopcock. After the device was placed, esophageal and gastric balloons were connected via polyethylene tubes to a pressure transducer box system (KT1D-2, Kleistek, Bari, Italy). The catheter was slowly withdrawn into the lower third of the esophagus, as indicated by the appearance of cardiac artifacts on the esophageal trace, and the esophageal balloon filling volume was adjusted to obtain the optimal $\mathrm{P}_{\mathrm{es}}$ transmission. ${ }^{22,23}$ At this point, two external manual compressions on the rib cage were applied during an expiratory pause, and the simultaneous positive deflections of the airways and esophageal pressure traces were compared. ${ }^{24-28}$ Finally, after the definitive catheter position was achieved, the end-expiratory and end-inspiratory calibrated $\mathrm{P}_{\mathrm{es}}$ was computed. ${ }^{23}$

Once pneumoperitoneum and Trendelenburg position were achieved, a 1-min recruitment maneuver was applied. ${ }^{14}$ The ventilator was switched to pressure control mode, an inspiratory/expiratory ratio of 1:1 was set, a peak inspiratory pressure gradient (above PEEP) was fixed at $20 \mathrm{~cm} \mathrm{H}_{2} \mathrm{O}$, and PEEP was progressively applied to obtain a stepwise increase of peak inspiratory pressure to 30,35 , and $40 \mathrm{~cm}$ $\mathrm{H}_{2} \mathrm{O}$ every 3 breaths. The final recruiting pressure of $40 \mathrm{~cm}$ $\mathrm{H}_{2} \mathrm{O}$ was carried out over 6 breaths. The ventilator was then switched to volume control mode.

\section{Study Protocol}

After lung recruitment, subjects were randomly assigned to a treatment group using a computer-generated randomization sequence; the assignment was reported to the attending physician before the subject's admission to the operating room.
In the $\mathrm{V}_{\text {Gas-guided }}$ group, PEEP and $\mathrm{F}_{\mathrm{IO}_{2}}$ were chosen by the robotic surgery anesthesia staff to maintain a $\mathrm{S}_{\mathrm{pO}_{2}}>$ $94 \%$ and a plateau respiratory system pressure $\left(\mathrm{P}_{\text {plat }}\right)<30$ $\mathrm{cm} \mathrm{H}_{2} \mathrm{O}$ according to our institutional protocol $\left(\mathrm{F}_{\mathrm{IO}_{2}}\right.$ to oxygenation target; PEEP of $0-5 \mathrm{~cm} \mathrm{H}_{2} \mathrm{O}$ for body mass index $<30 \mathrm{~kg} / \mathrm{m}^{2}$ and $5-10 \mathrm{~cm} \mathrm{H}_{2} \mathrm{O}$ for body mass index $\geq 30 \mathrm{~kg} / \mathrm{m}^{2}$ ). When $\mathrm{S}_{\mathrm{pO}_{2}}$ decreased to $\leq 94 \%, \mathrm{~F}_{\mathrm{IO}_{2}}$ was increased first, followed by PEEP, after excluding common possible causes such as endotracheal tube misplacement or airway secretions. ${ }^{29,30}$ If $\mathrm{S}_{\mathrm{pO}_{2}}$ persistently remained $\leq 94 \%$, a recruitment maneuver was performed with continuous hemodynamic monitoring.

In the $\mathrm{V}_{\text {Pes-guided }}$ group, PEEP was delivered to obtain an expiratory transpulmonary pressure $\geq 0 \mathrm{~cm} \mathrm{H}_{2} \mathrm{O}$. Furthermore, an upper limit of $20 \mathrm{~cm} \mathrm{H}_{2} \mathrm{O}$ of inspiratory transpulmonary pressure was set.

Tidal volume was chosen based on ideal body weight (6$8 \mathrm{~mL} / \mathrm{kg}$ ), the inspiratory/expiratory ratio was $1: 2$, and the breathing frequency was set to maintain an end-tidal carbon dioxide value $\leq 55 \mathrm{~mm} \mathrm{Hg}$ in both arms. ${ }^{3,31}$ Furthermore, recruitment maneuvers, as previously described, could be delivered according to clinical judgment and if $\mathrm{S}_{\mathrm{pO}_{2}}$ was $<94 \%$. During recovery from anesthesia, subjects were transferred to the postanesthesia care unit while spontaneously breathing room air or, whenever required, oxygen via Venturi face mask, at which time they underwent a new lung ultrasound aeration evaluation.

Study steps were defined as follows (Figure 1): baseline, in the absence of external PEEP (T0), randomization immediately after recruitment maneuver (T1), $20 \mathrm{~min}$ (T2), $60 \mathrm{~min}$ (T3), and $120 \mathrm{~min}$ after application of the randomized ventilatory strategy (T4), and at the end of surgery, in a supine position, after elimination of pneumoperitoneum (T5).

\section{Measurements}

Demographic characteristics such as sex, age, ASA physical status, body mass index, and ideal body weight were obtained for each subject. Arterial $\mathrm{pH}$, the ratio of arterial partial pressure of oxygen to the fraction of inspired oxygen oxygenation $\left(\mathrm{P}_{\mathrm{aO}_{2}} / \mathrm{F}_{\mathrm{IO}_{2}}\right)$, arterial carbon dioxide partial pressure, and lactate were assessed at randomization, at $60 \mathrm{~min}$, at 120 min, and at the end of surgery. Hemodynamic status was continuously assessed throughout the study; mean arterial blood pressure and heart rate were collected from $\mathrm{T} 0$ to $\mathrm{T} 5$.

Flow and airway pressure were obtained with a heated pneumotachograph (Fleisch no. 2; Fleisch, Lausanne, Switzerland) installed between the endotracheal tube and the respiratory circuit. Esophageal and gastric pressures, together with flow and airway pressure signals, were recorded, digitalized, and collected via a dedicated acquisition system and software on a personal computer (ICU Lab, Kleistek, Bari, Italy). Esophageal balloon calibration 


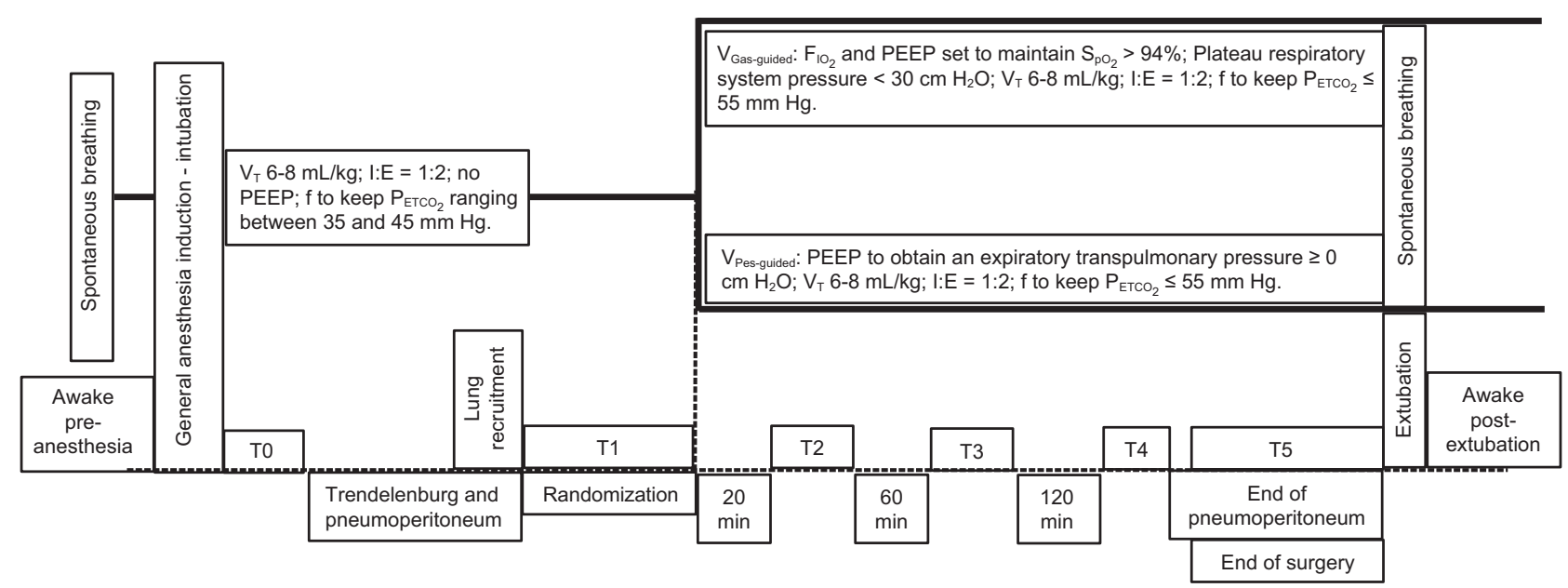

Fig. 1. Study time points. $V_{T}=$ tidal volume; $I: E=$ mechanical inspiratory-expiratory ratio; $f=$ breathing frequency; $P_{E T C O}=$ end-tidal carbon dioxide partial pressure; $\mathrm{F}_{\mathrm{IO}_{2}}=$ inspiratory oxygen fraction; $\mathrm{S}_{\mathrm{pO}_{2}}=$ peripheral oxygen saturation; $\mathrm{V}_{\mathrm{Gas} \text {-guided }}=$ conventional low-tidal ventilation with $\mathrm{PEEP}$ set according to gas exchange; $\mathrm{V}_{\mathrm{Pes} \text {-guided }}=$ low-tidal ventilation tailoring $\mathrm{PEEP}$ according to esophageal pressure.

was performed throughout the anesthesia period (T0-T5) during any change in PEEP, body position, or pneumoperitoneum pressure. ${ }^{23}$ We created a dedicated spreadsheet (Excel, Microsoft, Redmond, Washington) to compute the calibrated esophageal pressure and respiratory mechanics at optimal filling volume.

At each step from T0 to T5, occlusion maneuvers at both end-expiration and end-inspiration were performed to measure static pressures in the airways $\left(\mathrm{PEEP}_{\text {tot }}, \mathrm{P}_{\text {plat }}\right)$ and in the chest. These values were used to compute static expiratory and inspiratory transpulmonary pressures. Plateau elastance-derived transpulmonary pressure was also calculated. ${ }^{32,33}$ Peak inspiratory pressure, tidal volume, and inspiratory flow were also noted. Airway resistance, elastance, and driving pressure of respiratory system, chest wall, and lung were calculated.

Lung ultrasounds were assessed before anesthesia induction and after recovery from anesthesia in the spontaneously breathing subjects. ${ }^{19-21}$ On each hemithorax, 6 ultrasound regions were identified as follows: by using anterior and posterior axillary as anatomical landmarks, each side was divided into 3 zones that were furtherly partitioned into an upper and lower area. These zones were scanned with a linear or convex probe. For each explored region, the worst finding was reported according to the following rating: normal: 0; well-separated B-lines: 1; coalescent B-lines: 2; and consolidation: 3 . The cumulative lung ultrasound score corresponds to the sum of each examined region score and ranged between 0 (minimum score, normal lungs) and 36 (maximum score, both consolidated lungs).

Anesthesiologic and surgical outcomes such as surgery, pneumoperitoneum, duration of Trendelenburg position, intraabdominal pressure applied, total number of lung recruiting maneuvers performed for each subject, the number of subjects in whom vasoactive drugs were administrated, diuresis, and fluids administration rate were acquired. Length of hospital stay was also recorded.

\section{Statistical Analysis}

To detect an average intraoperative $\mathrm{P}_{\mathrm{aO}_{2}} / \mathrm{F}_{\mathrm{IO}_{2}}$ difference of $80 \mathrm{~mm} \mathrm{Hg}$ and a standard deviation (SD) of $60 \mathrm{~mm} \mathrm{Hg}$ (standardized mean difference $=1.3$ ) at $120 \mathrm{~min}$ after randomization between the 2 study groups, considering the time needed for the PEEP to affect oxygenation, ${ }^{34}$ a sample size of 28 subjects (14 per group, randomization ratio 1:1) was deemed suitable (power $80 \%$, alpha 0.05 ). This difference considered the oxygenation improvement induced by PEEP as reported in previous studies. ${ }^{17,35}$ Continuous variables were reported as mean $\pm \mathrm{SD}$. Comparison between groups was assessed using the Mann-Whitney test with the Holm-Sidak method correction. The Friedman test and the Dunn test correction were applied for trend analysis. Categorical variables were evaluated with the Fisher exact test. $P$ values $<.05$ were considered statistically significant. Statistical analyses were conducted using Prism 6.0 software (Graph-pad, La Jolla, California).

\section{Results}

\section{Demographic and Surgery Data}

From September 2017 to January 2019, 49 nonconsecutive patients undergoing elective pelvic robotic surgery were considered eligible, of whom 31 were included in the study (Figure 2). Finally, 28 subjects successfully 


\section{SETTING PEEP INTRAOPERATIVELY}

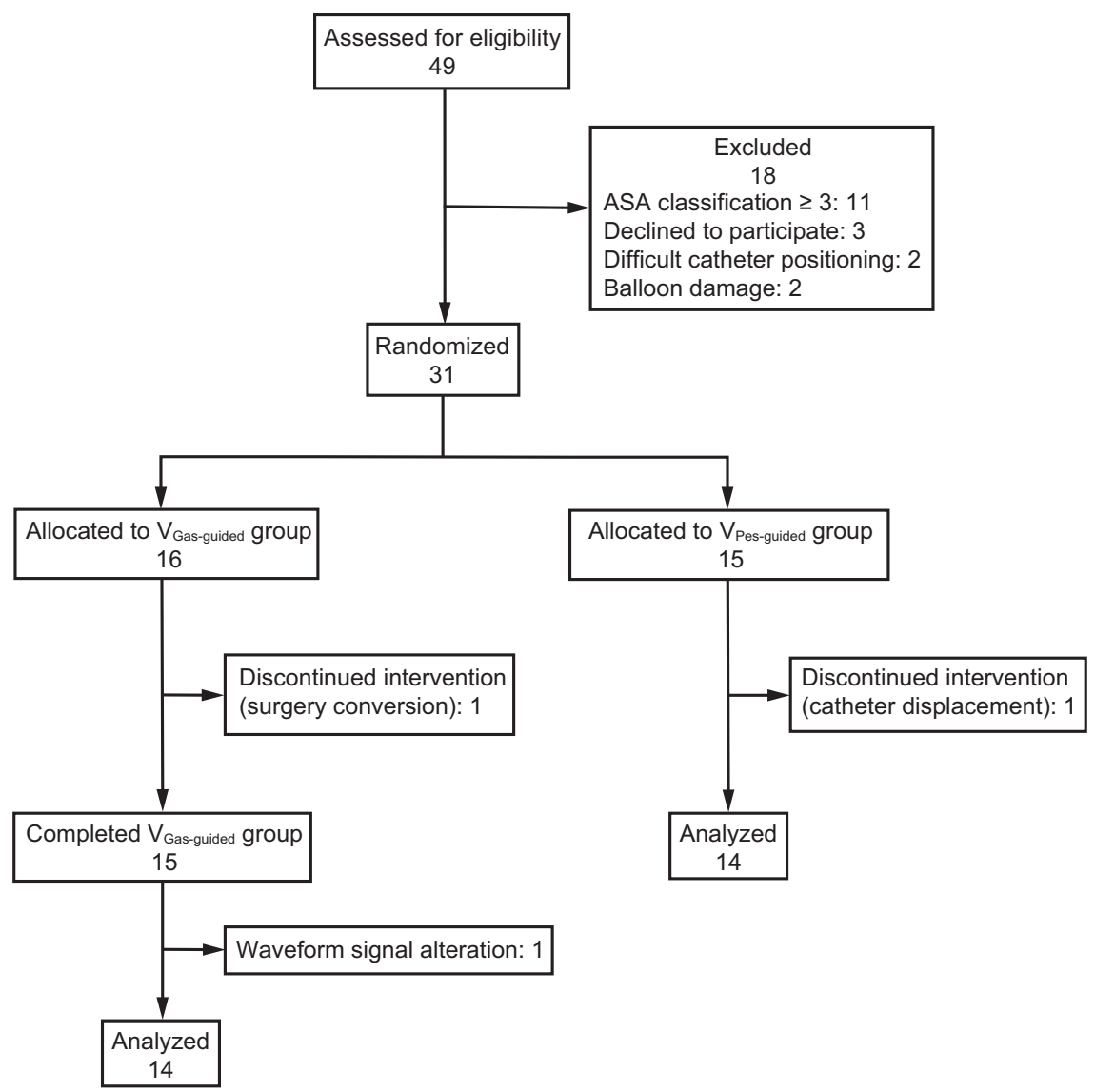

Fig. 2. Flow chart. $A S A=$ American Society of Anesthesiologists; $V_{\text {Gas-guided }}=$ conventional low-tidal ventilation with $P E E P$ set according to gas exchange; $V_{\text {Pes-guided }}=$ low-tidal ventilation tailoring PEEP according to esophageal pressure.

Table 1. Demographic Characteristics

\begin{tabular}{lrcc}
\hline \hline \multicolumn{1}{c}{ Subjects } & $\mathrm{V}_{\text {Gas-guided }}$ & $\mathrm{V}_{\text {Pes-guided }}$ & $P$ \\
\hline Male & $8(57.1)$ & $7(50)$ & .99 \\
Age, y & $62.5 \pm 9.5$ & $62.8 \pm 11.4$ & .92 \\
ASA classification II & $12(85.7)$ & $11(78.6)$ & .99 \\
Body mass index, $\mathrm{kg} / \mathrm{m}^{2}$ & $25.4 \pm 2.6$ & $24.1 \pm 4.1$ & .25 \\
Ideal body weight, $\mathrm{kg}$ & $63.2 \pm 9.0$ & $61.9 \pm 8.2$ & .74
\end{tabular}

$\overline{\text { Data are presented as } n}(\%)$ or mean \pm SD. $n=14$ subjects in each group.

$\mathrm{V}_{\text {Gas-guided }}=$ conventional low-tidal ventilation with PEEP set according to gas exchange

$\mathrm{V}_{\text {Pes-guided }}=$ low-tidal ventilation tailoring PEEP according to esophageal pressure

ASA $=$ American Society of Anesthesiologists

completed the study and were analyzed. Demographic characteristics were similar in the 2 groups (Table 1).

\section{Ventilator Settings}

As reported in Table 2, applied PEEP was lower in the $\mathrm{V}_{\text {Gas-guided }}$ group compared to the $\mathrm{V}_{\text {Pes-guided }}$ group at $\mathrm{T} 2$ $(P<.001)$, T3 $(P<.001)$, and T4 $(P=.002)$. At T5, PEEP decreased compared to T2, T3 and T4 in the $\mathrm{V}_{\text {Pes-guided }}$ group, without difference with respect to $\mathrm{V}_{\mathrm{Gas} \text {-guided }}$ group. Tidal volume, breathing frequency, and minute ventilation were comparable in both study groups. Breathing frequency and minute ventilation progressively increased from T0 to $\mathrm{T} 3$ in both ventilatory strategies.

\section{Gas Exchange}

The effects on arterial blood gases exerted by these ventilatory strategies are depicted in Table 3. After randomization, $\mathrm{P}_{\mathrm{aO}_{2}} / \mathrm{F}_{\mathrm{IO}_{2}}$ progressively diverged in the subjects, and it was higher in the $\mathrm{V}_{\text {Pes-guided }}$ group at $\mathrm{T} 3(P=$ $.02)$, T4 $(P=.008)$, and T5 $(P=.009)$ compared to the $\mathrm{V}_{\text {Gas-guided }}$ group; this difference was ascribed to an oxygenation improvement in the $\mathrm{V}_{\text {Pes-guided }}$ group but not in the $\mathrm{V}_{\text {Gas-guided }}$ group. $\mathrm{F}_{\mathrm{IO}_{2}}$, arterial carbon dioxide partial pressure, and lactate levels did not differ among groups.

\section{Respiratory Mechanics}

Static pressures, elastances, and driving pressures of the global respiratory system, chest wall, and lung are reported in Table 4. PEEP $_{\text {tot }}$ was lower at T2 $(P<.001)$, 


\section{SETTING PEEP INTRAOPERATIVELY}

Table 2. Volume Control Mode Settings

\begin{tabular}{|c|c|c|c|c|c|c|}
\hline Parameters & T0 & $\mathrm{T} 1$ & $\mathrm{~T} 2$ & $\mathrm{~T} 3$ & $\mathrm{~T} 4$ & T5 \\
\hline \multicolumn{7}{|l|}{$\mathrm{V}_{\mathrm{T}}, \mathrm{mL} / \mathrm{kg}$} \\
\hline $\mathrm{V}_{\text {Gas-guided }}$ & $7.6 \pm 0.3$ & $7.6 \pm 0.2$ & $7.8 \pm 0.2$ & $7.8 \pm 0.2$ & $7.7 \pm 0.2$ & $7.7 \pm 0.3$ \\
\hline $\mathrm{V}_{\text {Pes-guided }}$ & $7.6 \pm 0.3$ & $7.6 \pm 0.3$ & $7.7 \pm 0.3$ & $7.7 \pm 0.4$ & $7.7 \pm 0.4$ & $7.8 \pm 0.3$ \\
\hline \multicolumn{7}{|c|}{ Breathing frequency, breaths/min } \\
\hline $\mathrm{V}_{\text {Gas-guided }}$ & $14 \pm 1$ & $15 \pm 2$ & $17 \pm 3 \dagger$ & $18 \pm 2 \dagger+$ & $18 \pm 2 \dagger$ & $18 \pm 2+\neq$ \\
\hline $\mathrm{V}_{\text {Pes-guided }}$ & $14 \pm 1$ & $15 \pm 1$ & $17 \pm 3$ & $19 \pm 3 \dagger+$ & $20 \pm 4+\hbar$ & $20 \pm 4 \uparrow \neq$ \\
\hline \multicolumn{7}{|c|}{ Minute ventilation, $\mathrm{L} / \mathrm{min}$} \\
\hline $\mathrm{V}_{\text {Gas-guided }}$ & $6.1 \pm 2.0$ & $6.4 \pm 2.2$ & $7.1 \pm \dagger$ & $7.7 \pm 3.1 \dagger \neq$ & $8.2 \pm 2.6+\neq$ & $8.2 \pm 2.6 \dagger+$ \\
\hline $\mathrm{V}_{\text {Pes-guided }}$ & $6.2 \pm 1.8$ & $6.3 \pm 2.3$ & $7.2 \pm 3.2$ & $7.9 \pm 3.5+\neq$ & $8.3 \pm 3.7+\neq$ & $8.1 \pm 3.4 \dagger \neq$ \\
\hline \multicolumn{7}{|l|}{$\mathrm{PEEP}, \mathrm{cm} \mathrm{H}_{2} \mathrm{O}$} \\
\hline $\mathrm{V}_{\text {Gas-guided }}$ & $0 \pm 0$ & $0 \pm 0$ & $5.1 \pm 2.3^{*} \dagger+$ & $5.1 \pm 2.0^{*}+\ddagger$ & $5.2 \pm 2.1 * \dagger+$ & $5.9 \pm 2.6 \dagger+$ \\
\hline $\mathrm{V}_{\text {Pes-guided }}$ & $0 \pm 0$ & $0 \pm 0$ & $11.2 \pm 4.6+\div$ & $11.6 \pm 4.7 \dagger \neq$ & $10.4 \pm 5.3+\neq$ & $5.5 \pm 2.7 \S$ \\
\hline \multicolumn{7}{|c|}{ Data are presented as mean $\pm \mathrm{SD}$. } \\
\hline \multirow{2}{*}{\multicolumn{7}{|c|}{$\begin{array}{l}* \mathrm{~V}_{\text {Gas-guided }} \text { vs } \mathrm{V}_{\text {Pes-guided }}(P<.05) \\
\dagger \text { vs T0 }(P<.05) .\end{array}$}} \\
\hline & & & & & & \\
\hline \multicolumn{7}{|c|}{$\doteqdot \mathrm{vs} \mathrm{T} 1(P<.05)$} \\
\hline \multicolumn{7}{|c|}{$\S$ vs T2, T3, and T4 $(P<.05)$} \\
\hline \multicolumn{7}{|c|}{$\mathrm{T} 0=$ baseline } \\
\hline \multicolumn{7}{|c|}{$\mathrm{T} 1=$ after recruitment maneuver, following pneumoperitoneum and definitive Trendelenburg position } \\
\hline \multicolumn{7}{|c|}{$\mathrm{T} 2=20 \mathrm{~min}$ after randomization } \\
\hline \multicolumn{7}{|c|}{$\mathrm{T} 3=60 \mathrm{~min}$ after randomization } \\
\hline \multicolumn{7}{|c|}{$\mathrm{T} 4=120 \mathrm{~min}$ after randomization } \\
\hline \multicolumn{7}{|c|}{$\mathrm{T} 5=$ end of surgery, in supine position, after pneumoperitoneum elimination } \\
\hline \multicolumn{7}{|c|}{$\mathrm{V}_{\text {Gas-guided }}=$ conventional low-tidal ventilation with PEEP set according to gas exchange } \\
\hline \multicolumn{7}{|c|}{$\mathrm{V}_{\text {Pes-guided }}=$ low-tidal ventilation tailoring PEEP according to esophageal pressure } \\
\hline $\mathrm{V}_{\mathrm{T}}=$ tidal volume & & & & & & \\
\hline
\end{tabular}

Table 3. Arterial Blood Gases

\begin{tabular}{|c|c|c|c|c|}
\hline Parameters & Randomization & At $60 \mathrm{Min}$ & At $120 \mathrm{Min}$ & $\begin{array}{l}\text { At End of } \\
\text { Surgery }\end{array}$ \\
\hline \multicolumn{5}{|c|}{$\mathrm{P}_{\mathrm{aO}_{2}} / \mathrm{F}_{\mathrm{IO}_{2}}, \mathrm{~mm} \mathrm{Hg}$} \\
\hline $\mathrm{V}_{\text {Gas-guided }}$ & $264 \pm 66$ & $308 \pm 95^{*}$ & $308 \pm 81^{*}$ & $312 \pm 95^{*}$ \\
\hline $\mathrm{V}_{\text {Pes-guided }}$ & $307 \pm 102$ & $388 \pm 90 \dagger$ & $400 \pm 90 \dagger$ & $402 \pm 95 \dagger$ \\
\hline \multicolumn{5}{|l|}{$\mathrm{F}_{\mathrm{IO}_{2}}$} \\
\hline $\mathrm{V}_{\text {Gas-guided }}$ & $0.50 \pm 0.06$ & $0.47 \pm 0.06$ & $0.48 \pm 0.07$ & $0.48 \pm 0.08$ \\
\hline $\mathrm{V}_{\text {Pes-guided }}$ & $0.47 \pm 0.05$ & $0.42 \pm 0.07$ & $0.41 \pm 0.07$ & $0.41 \pm 0.07$ \\
\hline \multicolumn{5}{|l|}{$\mathrm{P}_{\mathrm{aCO}_{2}}, \mathrm{~mm} \mathrm{Hg}$} \\
\hline $\mathrm{V}_{\text {Gas-guided }}$ & $47.1 \pm 4.6$ & $44.0 \pm 2.9$ & $42.3 \pm 2.9 \dagger$ & $42.0 \pm 3.2$ \\
\hline $\mathrm{V}_{\text {Pes-guided }}$ & $44.5 \pm 6.1$ & $42.7 \pm 5.1$ & $41.1 \pm 3.9$ & $40.6 \pm 3.7$ \\
\hline \multicolumn{5}{|l|}{$\mathrm{pH}$} \\
\hline $\mathrm{V}_{\text {Gas-guided }}$ & $7.33 \pm 0.04$ & $7.33 \pm 0.03$ & $7.33 \pm 0.03$ & $7.32 \pm 0.02$ \\
\hline $\mathrm{V}_{\text {Pes-guided }}$ & $7.33 \pm 0.05$ & $7.34 \pm 0.04$ & $7.35 \pm 0.03$ & $7.35 \pm 0.04$ \\
\hline \multicolumn{5}{|l|}{ Lactate, $\mathrm{mmol} / \mathrm{L}$} \\
\hline $\mathrm{V}_{\text {Gas-guided }}$ & $0.52 \pm 0.12$ & $0.59 \pm 0.21$ & $0.64 \pm 0.21$ & $0.73 \pm 0.21 \dagger$ \\
\hline $\mathrm{V}_{\text {Pes-guided }}$ & $0.49 \pm 0.12$ & $0.55 \pm 0.19$ & $0.60 \pm 0.21$ & $0.64 \pm 0.22 \dagger$ \\
\hline \\
\hline \multicolumn{5}{|c|}{$\begin{array}{l}* \mathrm{~V}_{\text {Gas-guided }} \text { vs } \mathrm{V}_{\text {Pes-guided }}(P<.05) \\
\dagger \text { vs randomization }(P<.05)\end{array}$} \\
\hline \multicolumn{5}{|c|}{$\mathrm{V}_{\text {Gas-guided }}=$ conventional low-tidal ventilation with PEEP set according to gas exchange } \\
\hline \multicolumn{5}{|c|}{$\mathrm{V}_{\text {Pes-guided }}=$ low-tidal ventilation tailoring PEEP according to esophageal pressure } \\
\hline \multicolumn{5}{|c|}{$\mathrm{P}_{\mathrm{aO}_{2}} / \mathrm{F}_{\mathrm{IO}_{2}}=$ ratio of arterial partial pressure of oxygen to the fraction of inspired oxygen } \\
\hline
\end{tabular}

T3 $(P<.001)$, and T4 $(P<.001)$ in the $\mathrm{V}_{\text {Gas-guided }}$ group compared to the $\mathrm{V}_{\text {Pes-guided }}$ group. This difference was eliminated at T5 when PEEP tot was similar in both groups. Peak inspiratory pressure, $\mathrm{P}_{\text {plat}}$, and inspiratory and expiratory chest wall pressure increased from T1 to T2, T3, and T4 with PEEP application and finally diminished at T5 to values similar to baseline in both groups. Expiratory transpulmonary pressure was lower at T2 $(P<.001), \mathrm{T} 3(P<.001)$, and T4 $(P=.002)$ in the $\mathrm{V}_{\text {Gas-guided }}$ group compared to the $\mathrm{V}_{\text {Pes-guided }}$ group. Inspiratory transpulmonary pressure was lower in the $\mathrm{V}_{\text {Gas-guided }}$ group than in the $\mathrm{V}_{\text {Pes-guided }}$ group at $\mathrm{T} 3$ $(P=.003)$ and T4 $(P=.005)$.

Figure 3 depicts elastance and driving pressure trends during the study. Respiratory system and chest wall elastance and driving pressure worsened from T0 to T1 in both study groups. PEEP administration improved elastance and driving pressure from $\mathrm{T} 4$ to $\mathrm{T} 5$ in the $\mathrm{V}_{\text {Gas-guided }}$ group and from $\mathrm{T} 2$ to the end of surgery in the $\mathrm{V}_{\text {Pes-guided }}$ group. Respiratory system elastance was higher in the $\mathrm{V}_{\text {Gas-guided }}$ group compared to the $\mathrm{V}_{\text {Pes-guided }}$ group at $\mathrm{T} 2$ (33.4 \pm 10.7 vs $24.2 \pm 7.3 \mathrm{~cm} \mathrm{H} 2 \mathrm{O} / \mathrm{L}, P=.001)$ and $\mathrm{T} 3$ (31.9 \pm 8.5 vs $24.1 \pm 5.4 \mathrm{~cm} \mathrm{H} \mathrm{O} / \mathrm{L}, P=.006)$, whereas chest wall elastance was greater only at T2 (18.2 \pm 6.3 vs $13.2 \pm$ $\left.5.8 \mathrm{~cm} \mathrm{H}_{2} \mathrm{O} / \mathrm{L}, P=.007\right)$. Respiratory system driving pressure was higher in the $\mathrm{V}_{\mathrm{Gas} \text {-guided }}$ group compared to the

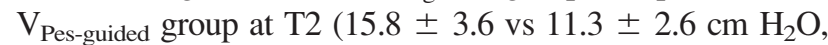
$P<.001)$, T3 $\left(15.5 \pm 3.4\right.$ vs $11.3 \pm 2.0 \mathrm{~cm} \mathrm{H} \mathrm{H}_{2} \mathrm{O}, P<$ $.001)$, T4 (14.5 \pm 3.4 vs $\left.11.3 \pm 1.8 \mathrm{~cm} \mathrm{H}_{2} \mathrm{O}, P=.005\right)$, and T5 (10.8 \pm 2.6 vs $\left.8.5 \pm 1.6 \mathrm{~cm} \mathrm{H}_{2} \mathrm{O}, P=.01\right)$, whereas chest wall driving pressure was greater only at T2 $(8.7 \pm 2.2$ vs $\left.6.0 \pm 2.2 \mathrm{~cm} \mathrm{H}_{2} \mathrm{O}, P<.001\right)$, T3 $(8.8 \pm 2.7$ vs $6.1 \pm 1.9$ $\left.\mathrm{cm} \mathrm{H}_{2} \mathrm{O}, P<.001\right)$, and $\mathrm{T} 4(7.2 \pm 2.3$ vs $5.2 \pm 1.6 \mathrm{~cm}$ $\left.\mathrm{H}_{2} \mathrm{O}, P=.007\right)$.

\section{Lung Ultrasound and Outcomes}

As shown in Figure 4, the lung ultrasound score worsened after extubation in both groups, reaching higher values 
Table 4. Respiratory Mechanics

\begin{tabular}{|c|c|c|c|c|c|c|}
\hline \multirow{2}{*}{ Parameters } & \multicolumn{6}{|c|}{ Study Steps } \\
\hline & T0 & $\mathrm{T} 1$ & $\mathrm{~T} 2$ & $\mathrm{~T} 3$ & $\mathrm{~T} 4$ & $\mathrm{~T} 5$ \\
\hline \multicolumn{7}{|c|}{$\mathrm{PEEP}_{\text {tot }}, \mathrm{cm} \mathrm{H}_{2} \mathrm{O}$} \\
\hline $\mathrm{V}_{\text {Gas-guided }}$ & $0.2 \pm 0.8$ & $0.6 \pm 1.6$ & $5.2 \pm 2.4 *+\neq$ & $5.3 \pm 2.0^{*} \dagger+$ & $5.5 \pm 2.2 * \dagger+$ & $6.1 \pm 2.7 \dagger t$ \\
\hline $\mathrm{V}_{\text {Pes-guided }}$ & $0.2 \pm 0.6$ & $0.9 \pm 2.4$ & $11.4 \pm 4.8 \dagger \ddagger$ & $11.8 \pm 4.9 \dagger \dagger$ & $10.6 \pm 5.5 \dagger \neq$ & $5.6 \pm 2.7 \S$ \\
\hline \multicolumn{7}{|l|}{$\mathrm{PIP}, \mathrm{cm} \mathrm{H}_{2} \mathrm{O}$} \\
\hline $\mathrm{V}_{\text {Gas-guided }}$ & $15.1 \pm 3.4$ & $25.7 \pm 9.4 \dagger$ & $27.4 \pm 5.5 \dagger$ & $29.5 \pm 5.8 \dagger+$ & $27.6 \pm 5.8 \dagger$ & $22.6 \pm 4.1 \S$ \\
\hline$V_{\text {Pes-guided }}$ & $14.8 \pm 4.1$ & $21.9 \pm 5.7$ & $29.2 \pm 4.2 \dagger+$ & $31.3 \pm 6.0 \dagger+$ & $29.0 \pm 6.2 \dagger$ & $20.4 \pm 3.1 \S$ \\
\hline \multicolumn{7}{|l|}{$\mathrm{P}_{\text {plat }}, \mathrm{cm} \mathrm{H} \mathrm{H}_{2} \mathrm{O}$} \\
\hline $\mathrm{V}_{\text {Gas-guided }}$ & $9.8 \pm 2.6$ & $18.2 \pm 4.0$ & $21.0 \pm 3.9 \dagger$ & $20.8 \pm 3.8 \dagger \dagger$ & $20.0 \pm 3.9 \dagger$ & $16.9 \pm 3.0 \S$ \\
\hline $\mathrm{V}_{\text {Pes-guided }}$ & $9.7 \pm 2.9$ & $15.9 \pm 4.5$ & $22.7 \pm 4.3 \dagger+$ & $23.0 \pm 4.9 \dagger \dagger$ & $22.0 \pm 5.8 \dagger+$ & $14.1 \pm 3.1 \S$ \\
\hline \multicolumn{7}{|c|}{$\mathrm{PE}_{\mathrm{CW}}, \mathrm{cm} \mathrm{H}_{2} \mathrm{O}$} \\
\hline $\mathrm{V}_{\text {Gas-guided }}$ & $4.4 \pm 1.8$ & $7.8 \pm 5.0$ & $9.7 \pm 5.3 \dagger$ & $9.1 \pm 4.6 \dagger$ & $9.1 \pm 5.0 \dagger$ & $7.5 \pm 2.8$ \\
\hline $\mathrm{V}_{\text {Pes-guided }}$ & $3.6 \pm 2.7$ & $6.9 \pm 4.9$ & $11.6 \pm 4.8 \dagger t$ & $11.1 \pm 5.5 \dagger \dagger$ & $10.0 \pm 6.1 \dagger$ & $5.8 \pm 4.4 \S$ \\
\hline \multicolumn{7}{|c|}{$\mathrm{PI}_{\mathrm{CW}}, \mathrm{cm} \mathrm{H}_{2} \mathrm{O}$} \\
\hline $\mathrm{V}_{\text {Gas-guided }}$ & $8.9 \pm 1.6$ & $17.3 \pm 4.6 \dagger$ & $18.3 \pm 4.9 \dagger$ & $17.9 \pm 4.5 \dagger$ & $16.3 \pm 5.2 \dagger$ & $11.5 \pm 2.4 \ddagger \S$ \\
\hline $\mathrm{V}_{\text {Pes-guided }}$ & $7.5 \pm 3.2$ & $15.0 \pm 4.7 \dagger$ & $17.6 \pm 3.9 \dagger$ & $17.2 \pm 5.2 \dagger$ & $15.2 \pm 5.8 \dagger$ & $9.0 \pm 3.6 \S$ \\
\hline \multicolumn{7}{|l|}{$\mathrm{PE}_{\mathrm{L}}, \mathrm{cm} \mathrm{H} \mathrm{H}_{2} \mathrm{O}$} \\
\hline $\mathrm{V}_{\text {Gas-guided }}$ & $-4.3 \pm 1.6$ & $-7.1 \pm 4.7$ & $-4.5 \pm 5.3^{*}$ & $-3.8 \pm 4.5^{*} \ddagger$ & $-3.6 \pm 4.7 *+$ & $-1.4 \pm 2.6+\ddagger \S$ \\
\hline $\mathrm{V}_{\text {Pes-guided }}$ & $-3.4 \pm 2.6$ & $-5.9 \pm 3.3$ & $-0.2 \pm 2.0 \dagger \ddagger$ & $0.7 \pm 1.3 \dagger \dagger$ & $0.5 \pm 1.3 \dagger \neq$ & $-0.2 \pm 2.6 \neq$ \\
\hline \multicolumn{7}{|l|}{$\mathrm{PI}_{\mathrm{L}}, \mathrm{cm} \mathrm{H}_{2} \mathrm{O}$} \\
\hline $\mathrm{V}_{\text {Gas-guided }}$ & $0.8 \pm 1.9$ & $0.9 \pm 2.6$ & $2.7 \pm 3.6$ & $2.9 \pm 2.7^{*} \ddagger$ & $3.7 \pm 2.9 * \dagger+$ & $5.4 \pm 3.0 \dagger t$ \\
\hline $\mathrm{V}_{\text {Pes-guided }}$ & $2.2 \pm 1.9$ & $0.9 \pm 1.8$ & $5.1 \pm 2.5 \$$ & $5.8 \pm 1.9 \dagger \dagger$ & $6.3 \pm 1.9 \dagger \ddagger$ & $5.4 \pm 2.7 \ddagger$ \\
\hline \multicolumn{7}{|c|}{$\mathrm{PI}_{\text {Lderived }}, \mathrm{cm} \mathrm{H}_{2} \mathrm{O}$} \\
\hline $\mathrm{V}_{\text {Gas-guided }}$ & $5.4 \pm 2.3$ & $8.3 \pm 4.0$ & $9.5 \pm 4.0 \dagger$ & $9.0 \pm 4.1 \dagger$ & $9.9 \pm 4.1 \dagger$ & $10.6 \pm 4.3 \dagger$ \\
\hline $\mathrm{V}_{\text {Pes-guided }}$ & $5.8 \pm 2.9$ & $7.5 \pm 3.9$ & $10.8 \pm 4.7 \dagger+$ & $10.7 \pm 4.3 \dagger$ & $11.8 \pm 4.8 \dagger \ddagger$ & $9.5 \pm 3.3$ \\
\hline \multicolumn{7}{|c|}{$\mathrm{R}_{\mathrm{aw}}, \mathrm{cm} \mathrm{H} \mathrm{H}_{2} \mathrm{O} / \mathrm{L} / \mathrm{s}$} \\
\hline $\mathrm{V}_{\text {Gas-guided }}$ & $11.9 \pm 3.8$ & $13.1 \pm 7.0$ & $11.5 \pm 4.9$ & $13.9 \pm 7.6$ & $11.6 \pm 6.8$ & $8.7 \pm 5.3 \dagger$ \\
\hline $\mathrm{V}_{\text {Pes-guided }}$ & $10.7 \pm 3.3$ & $12.8 \pm 4.9$ & $13.3 \pm 3.6$ & $13.2 \pm 6.4$ & $10.5 \pm 5.0$ & $10.0 \pm 5.6 \S$ \\
\hline 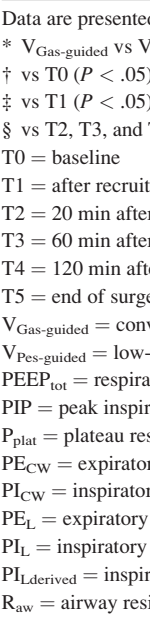 & $\begin{array}{l}\mathrm{n} \pm \mathrm{SD} \text {. } \\
(P<.05) \text {. } \\
\text {.05). } \\
\text { neuver, following } \\
\text { ization } \\
\text { ization } \\
\text { nization } \\
\text { pine position, after } \\
\text { low-tidal ventilati } \\
\text { tilation tailoring PI } \\
\text { em PEEP } \\
\text { ssure } \\
\text { system pressure } \\
\text { wall pressure } \\
\text { vall pressure } \\
\text { monary pressure } \\
\text { monary pressure } \\
\text { stance-derived tran }\end{array}$ & $\begin{array}{l}\text { peritoneum eliminat } \\
\text { PEEP set according } \\
\text { rding to esophageal }\end{array}$ & delenburg position & & & \\
\hline
\end{tabular}

in the $\mathrm{V}_{\text {Gas-guided }}$ group compared to the $\mathrm{V}_{\text {Pes-guided }}$ group. Hemodynamic status was not different between study populations as represented in Figure 5. As described in Table 5 , subjects in the $\mathrm{V}_{\text {Gas-guided }}$ group and the $\mathrm{V}_{\text {Pes-guided }}$ group experienced similar outcomes over the study duration. No difference in terms of length of hospital stay were noted between groups $(4 \pm 1$ vs $4 \pm 1 \mathrm{~d})$.

\section{Discussion}

The main findings of our pilot investigation can be summarized as follows: intraoperative oxygenation improved in the $\mathrm{V}_{\text {Pes-guided }}$ group while it remained stable in the $\mathrm{V}_{\mathrm{Gas} \text {-guided }}$ group; and respiratory system and chest wall mechanics were optimized with the $V_{\text {Pes-guided }}$ 

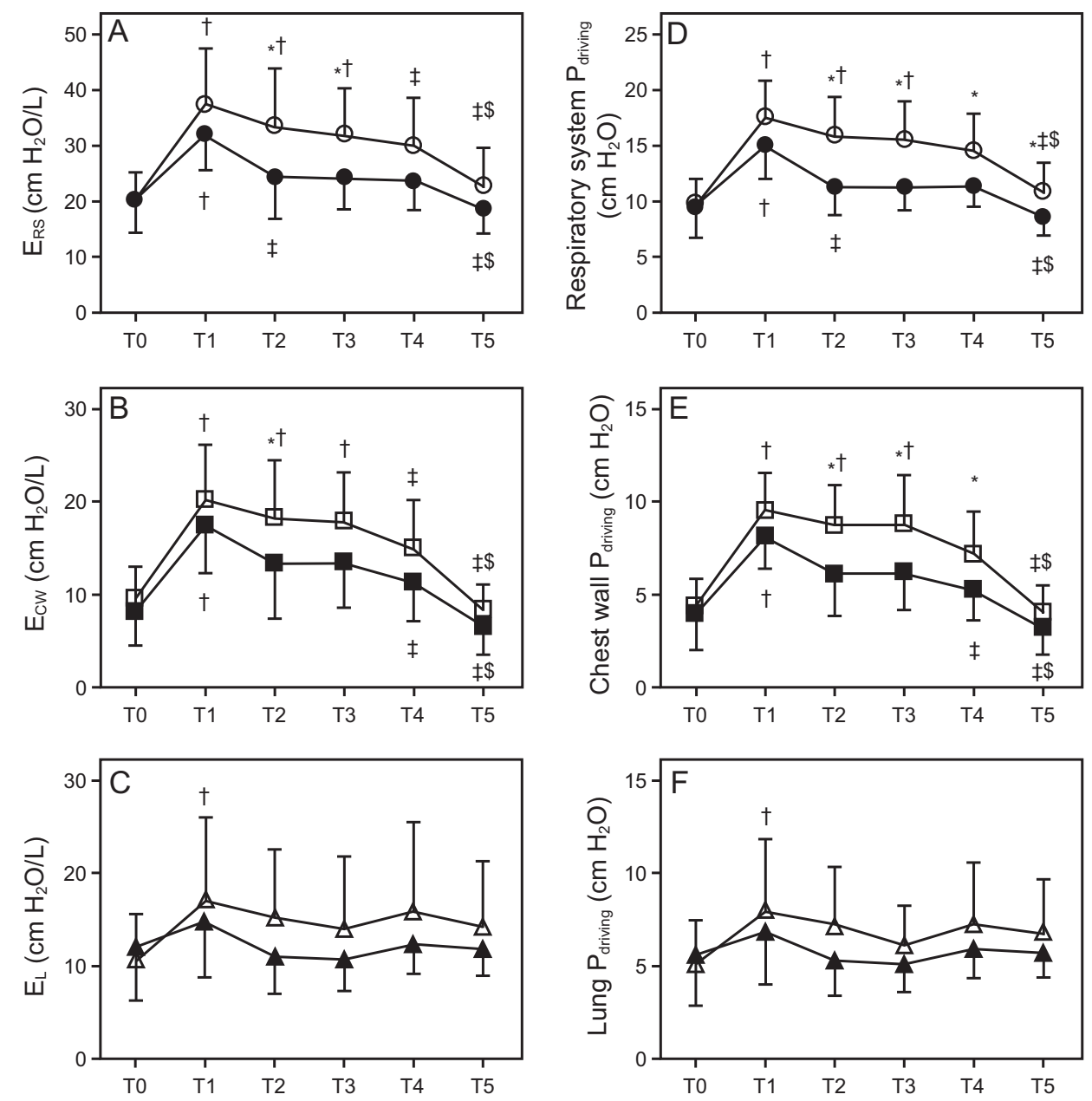

Fig. 3. Elastance and driving pressure. (A) Respiratory system elastance trend over entire study duration. (B) Chest wall elastance trend over entire study duration. (C) Lung elastance trend over entire study duration. (D) Respiratory system driving pressure trend over entire study duration.

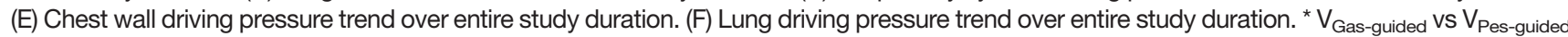
$(P<.05)$; vs T0 $(P<.05)$; vs T1, $P<.05$; $\$$ vs T2, T3, T4 $(P<.05)$. Data are presented as mean \pm SD. White symbols $=$ conventional low-tidal ventilation with PEEP set according to gas exchange; black symbols $=$ low-tidal ventilation tailoring PEEP according to esophageal pressure. $E=$ elastance; $\mathrm{P}_{\text {driving }}=$ driving pressure; T0 = baseline; $\mathrm{T} 1$ = after recruitment maneuver, following pneumoperitoneum and definitive Trendelenburg position; T2 = $20 \mathrm{~min}$ after randomization; $\mathrm{T} 3=60 \mathrm{~min}$ after randomization; $\mathrm{T} 4=120 \mathrm{~min}$ after randomization; T5 $=$ end of surgery, in supine position, after pneumoperitoneum elimination; $\mathrm{E}_{\mathrm{RS}}=$ respiratory system elastance; $\mathrm{E}_{\mathrm{CW}}=$ chest wall elastance; $\mathrm{E}_{\mathrm{L}}=$ lung elastance.

approach, with a final reduction of the driving pressure applied during mechanical ventilation. In addition, this strategy had no impact on hemodynamic status and the clinical outcomes that we explored. In the $\mathrm{V}_{\text {Pes-guided }}$ group, however, a nonsignificant incidence of higher vasoactive drug administration during the lung-recruiting maneuver, before randomization, was noted. This may be ascribed to a more pronounced propensity for hypotensive events observed in subjects in the $\mathrm{V}_{\text {Pes-guided }}$ group compared to the control arm.

General anesthesia, pneumoperitoneum, and Trendelenburg position affect oxygenation by promoting atelectasis. ${ }^{36}$ This phenomenon depends on a worsening of the functional residual capacity induced by a diaphragmatic cranial shift and stretch that usually occurs during robotic surgery. ${ }^{37-39}$ Moreover, the consequent impairment of respiratory mechanics and driving pressure can lead to ventilator-induced lung injury, which is a wellknown risk factor for postoperative pulmonary complications. ${ }^{10}$ Several trials have reported that PEEP application during pelvic robotic surgery improves oxygenation. ${ }^{17,40}$ A recent investigation conducted in subjects undergoing laparotomic and laparoscopic surgery reported the benefit of electrical impedance tomography-guided PEEP on intraoperative oxygenation compared to a low-PEEP ventilation strategy. ${ }^{35}$

In keeping with previous work, $\mathrm{P}_{\mathrm{aO}_{2}} / \mathrm{F}_{\mathrm{IO}_{2}}$ remained unchanged in the $\mathrm{V}_{\text {Gas-guided }}$ group after randomization, whereas it increased progressively to higher values in the $\mathrm{V}_{\text {Pes-guided }}$ group until the end of the surgery. Moreover, the 


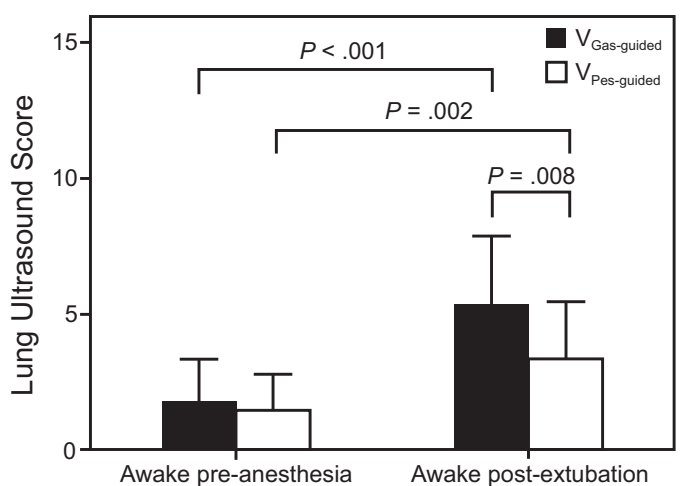

Fig. 4. Data are presented as mean $\pm \mathrm{SD}$. $\mathrm{V}_{\text {Gas-guided }}=$ conventional low-tidal ventilation with PEEP set according to gas exchange; $V_{\text {Pes-guided }}=$ low-tidal ventilation tailoring PEEP according to esophageal pressure.
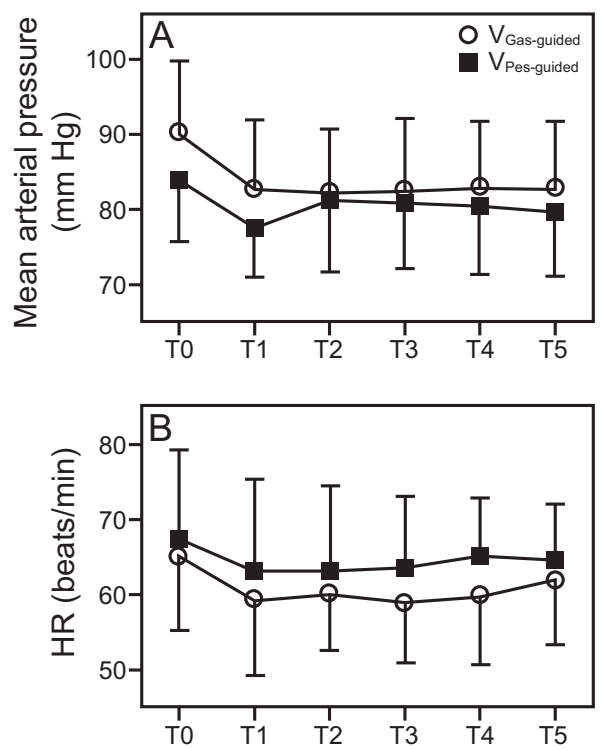

Fig. 5. Mean arterial blood pressure and heart rate. Data are presented as mean $\pm \mathrm{SD}$. T0 = baseline; $\mathrm{T} 1=$ after recruitment maneuver, following pneumoperitoneum and definitive Trendelenburg position; T2 $=20 \mathrm{~min}$ after randomization; T3 $=60$ min after randomization; T4 = $120 \mathrm{~min}$ after randomization; T5 = end of surgery, in supine position, after pneumoperitoneum elimination.

oxygenation levels achieved through $\mathrm{V}_{\text {Pes-guided }}$ PEEP were much higher compared to those obtained in the $\mathrm{V}_{\text {Gas-guided }}$ group. The increase in $\mathrm{P}_{\mathrm{aO}_{2}} / \mathrm{F}_{\mathrm{IO}_{2}}$ provided by the $\mathrm{V}_{\text {Pes-guided }}$ approach could be ascribed to levels of PEEP that were similar to values previously applied via electrical impedance tomography-guided PEEP. ${ }^{35}$ However, unlike the previous study, $\mathrm{V}_{\text {Pes-guided }}$ PEEP provided a more restrained oxygenation improvement. Several factors most likely explain this result. First, in our series, $\mathrm{P}_{\mathrm{aO}_{2}} / \mathrm{F}_{\mathrm{IO}_{2}}$ at randomization was similar between the study groups, whereas it was much higher in the electrical impedance tomography-guided group compared to the control group. Second, in the $\mathrm{V}_{\text {Gas-guided }}$ strategy, PEEP was not preset but was applied according to gas exchange. Finally, the lung-recruiting maneuver was planned after a decremental PEEP titration in the aforementioned investigation, whereas, in our study, it was applied following a PEEP-free volume-control stage. In this regard, lung recruitment was deemed mandatory in our study with the purpose of zeroing the lung history of each subject before PEEP application. ${ }^{18}$

PEEP has been proven to increase lung volume and counterbalance diaphragm cranial displacement induced by pneumoperitoneum and Trendelenburg position, improving chest wall and respiratory system mechanics with consequent reduction of driving pressure applied during mechanical ventilation. ${ }^{14,35,38}$

In this study, and in line with previous investigations, $\mathrm{V}_{\text {Pes-guided }}$ PEEP, when compared to $\mathrm{V}_{\text {Gas-guided }}$ PEEP, more incisively counteracted the negative effects of pneumoperitoneum and Trendelenburg position on chest wall and respiratory system reducing the respective elastance and driving pressure. Interestingly, under $\mathrm{V}_{\text {Pes-guided }}$ PEEP, respiratory system driving pressure was constantly less than $12.5 \mathrm{~cm} \mathrm{H}_{2} \mathrm{O}$, a well-defined limit of lower incidence of postoperative respiratory complications. ${ }^{41}$ It is likely that PEEP set using the $\mathrm{V}_{\text {Pes-guided }}$ strategy prevented substantial lung derecruitment and worsening of global lung elastance, which was evident in the lung ultrasound scans after recovery from anesthesia. Conversely, negative values of expiratory transpulmonary pressure in $\mathrm{V}_{\text {Gas-guided }}$ PEEP might have promoted both lung de-recruitment and tidal opening-closing of both alveoli and small airways, with opposite effects on lung elastance. De-recruitment increases lung elastance by diminishing the size of the lung, while cyclic opening and closing are associated with a tidal extra volume that decreases the measured lung elastance. ${ }^{42}$ This may explain why lung mechanics and gas exchange were partially uncoupled in our study population. In addition, $V_{\text {Pes-guided }}$ PEEP appears to be a safe ventilatory plan because average plateau elastance-derived transpulmonary pressure never exceeded the overdistention threshold of the lung. On the contrary, a ventilatory scheme applying PEEP to equalize pneumoperitoneum pressure or providing periodical recruiting maneuvers could improve oxygenation and mechanical properties, although it may put subjects at risk for overdistention and hemodynamic instability. ${ }^{43}$

$\mathrm{V}_{\text {Pes-guided }}$ PEEP, aiming to equalize expiratory transpulmonary pressure, could seem difficult to apply in routine laparoscopic surgery, but it could be particularly indicated in subjects who are at high risk of intraoperative lung de-recruitment and perioperative hypoxia to increase intraoperative oxygenation and ameliorate driving pressure. 


\section{SETTING PEEP INTRAOPERATIVELY}

Table 5. Clinical Outcomes

\begin{tabular}{|c|c|c|c|}
\hline Subjects & $\mathrm{V}_{\text {Gas-guided }}$ & $\mathrm{V}_{\text {Pes-guided }}$ & $P$ \\
\hline Surgery duration, min & $279 \pm 57$ & $263 \pm 69$ & .42 \\
\hline Pneumoperitoneum and Trendelenburg duration, min & $217 \pm 69$ & $214 \pm 69$ & .99 \\
\hline Average pneumoperitoneum pressure, $\mathrm{mm} \mathrm{Hg}$ & $8.5 \pm 3.1$ & $8.4 \pm 2.3$ & .92 \\
\hline Recruitment maneuver, $n$ & $1 \pm 0$ & $1 \pm 0$ & $>.99$ \\
\hline Fluid administration, $\mathrm{mL} / \mathrm{kg} / \mathrm{h}$ & $8.1 \pm 3.1$ & $8.5 \pm 3.1$ & .72 \\
\hline Diuresis, $\mathrm{mL} / \mathrm{kg} / \mathrm{h}$ & $1.8 \pm 0.9$ & $2.0 \pm 1.2$ & .83 \\
\hline Vasoactive administration (during recruitment maneuver), $n$ & $6(42.9)$ & $11(78.6)$ & .12 \\
\hline \multicolumn{4}{|c|}{$\begin{array}{l}\text { Data are presented as } n(\%) \text { or mean } \pm \text { SD. } n=14 \text { subjects in each group. } \\
\mathrm{V}_{\text {Gas-guided }}=\text { conventional low-tidal ventilation with PEEP set according to gas exchange } \\
\mathrm{V}_{\text {Pes-guided }}=\text { low-tidal ventilation tailoring PEEP according to esophageal pressure }\end{array}$} \\
\hline
\end{tabular}

Our study has several limitations that make it impossible to draw definitive conclusions on the real benefits of $\mathrm{V}_{\text {Pes-guided }}$ PEEP on oxygenation and respiratory mechanics. First, the study population was relatively small, although it was in line with a recent investigation conducted in an analogous laparoscopic setting. ${ }^{35}$ Second, it could be argued that a standardized high-PEEP or an approach applying PEEP according to compliance or driving pressure was not adopted in the $\mathrm{V}_{\text {Gas-guided }}$ group. However, our $\mathrm{V}_{\text {Gas-guided }}$ strategy completely replicated the control arm of mechanical ventilation settings proposed in a recent investigation supporting the need to individualize PEEP in subjects undergoing general anesthesia for laparotomic or laparoscopic surgery. ${ }^{35}$ Third, in the control group the administration of $\mathrm{F}_{\mathrm{IO}_{2}}$ and PEEP were guided by gas exchange in agreement with our institutional protocol. However, a strategy that promotes PEEP modification over $\mathrm{F}_{\mathrm{IO}_{2}}$ adjustment could have been more advantageous compared to that applied to our control group to improve respiratory function and gas exchange. Fourth, in evaluating chest wall and lung mechanics, it is worth considering the ventilation distribution between dependent and nondependent lung areas and the spatial pleural pressure gradients in the respiratory system. ${ }^{44}$ Finally, some inhomogeneity in surgical procedures must be considered in interpreting our data.

\section{Conclusions}

In our setting, oxygenation, respiratory system mechanics, and driving pressure, improved when a $\mathrm{V}_{\text {Pes-guided }}$ strategy was used, although no differences were detected in perioperative clinical outcomes. Our results need to be confirmed with future and larger investigations, conducted especially in subjects prone to develop intraoperative lung de-recruitment while undergoing elective pelvic robotic surgery.

\section{ACKNOWLEDGMENTS}

The authors wish to thank all the physicians and nurses of the robotic surgery block.

\section{REFERENCES}

1. Fanning J, Fenton B, Purohit M. Robotic radical hysterectomy. Am J Obstet Gynecol 2008;198(6):649.E1-649.E4.

2. Rao KR. Laparoscopic and robotic-assisted simple prostatectomy. World J Laparosc Surg 2012;5:137-138.

3. Valenza F, Chevallard G, Fossali T, Salice V, Pizzocri M, Gattinoni L. Management of mechanical ventilation during laparoscopic surgery. Best Pract Res Clin Anaesthesiol 2010;24(2):227-241.

4. Suh MK, Seong KW, Jung SH, Kim SS. The effect of pneumoperitoneum and Trendelenburg position on respiratory mechanics during pelviscopic surgery. Korean J Anesthesiol 2010;59(5):329-334.

5. Andersson LE, Bååth M, Thörne A, Aspelin P, Odeberg-Wernerman S. Effect of carbon dioxide pneumoperitoneum on development of atelectasis during anesthesia, examined by spiral computed tomography. Anesthesiology 2005;102(2):293-299.

6. Strang CM, Hachenberg T, Fredén F, Hedenstierna G. Development of atelectasis and arterial to end-tidal PCO 2-difference in a porcine model of pneumoperitoneum. Br J Anaesth 2009; 103(2):298-303.

7. Eichenberger A-S, Proietti S, Wicky S, Frascarolo P, Suter M, Spahn DR. Morbid obesity and postoperative pulmonary atelectasis: an underestimated problem. Anesth Analg 2002;95(6):1788-1792.

8. Fung YC. Stress, deformation, and atelectasis of the lung. Circ Res 1975;37(4):481-496.

9. Slutsky AS, Ranieri VM. Ventilator-induced lung injury. N Engl J Med 2013;369(22):2126-2136.

10. Neto AS, Hemmes SNT, Barbas CV, Beiderlinden M, FernandezBustamante A, Futier E, et al. Association between driving pressure and development of postoperative pulmonary complications in patients undergoing mechanical ventilation for general anaesthesia: a meta-analysis of individual patient data. Lancet Respir Med 2016; 4(4):272-280.

11. Futier E, Constantin JM, Paugam-Burtz C, Pascal J, Eurin M, Neuschwander A, et al. A trial of intraoperative low-tidal-volume ventilation in abdominal surgery. N Engl J Med 2013;369(5):428-437.

12. Futier E, Constantin JM, Pelosi P, Chanques G, Kwiatkoskwi F, Jaber S, Bazin JE. Intraoperative recruitment maneuver reverses detrimental pneumoperitoneum-induced respiratory effects in healthy weight and obese patients undergoing laparoscopy. Anesthesiology 2010;113 (6):1310-1319.

13. Eichler L, Truskowska K, Dupree A, Busch P, Goetz AE, Zöllner C. Intraoperative ventilation of morbidly obese patients guided by transpulmonary pressure. Obes Surg 2018;28(1):122-129.

14. Cinnella G, Grasso S, Spadaro S, Rauseo M, Mirabella L, Salatto P, et al. Effects of recruitment maneuver and positive end-expiratory pressure on respiratory mechanics and transpulmonary pressure during laparoscopic surgery. Anesthesiology 2013;118(1):114-122. 


\section{SETTING PEEP INTRAOPERATIVELY}

15. Talab HF, Zabani IA, Abdelrahman HS, Bukhari WL, Mamoun I, Ashour MA, et al. Intraoperative ventilatory strategies for prevention of pulmonary atelectasis in obese patients undergoing laparoscopic bariatric surgery. Anesth Analg 2009;109(5):1511-1516.

16. Maracajá-Neto LF, Verçosa N, Roncally AC, Giannella A, Bozza FA, Lessa MA. Beneficial effects of high positive end-expiratory pressure in lung respiratory mechanics during laparoscopic surgery. Acta Anaesthesiol Scand 2009;53(2):210-217.

17. Meininger D, Byhahn C, Mierdl S, Westphal K, Zwissler B. Positive end-expiratory pressure improves arterial oxygenation during prolonged pneumoperitoneum. Acta Anaesthesiol Scand 2005;49(6):778783 .

18. Talmor D, Sarge T, Malhotra A, O'Donnell CR, Ritz R, Lisbon A, et al. Mechanical ventilation guided by esophageal pressure in acute lung injury. N Engl J Med 2008;359(20):2095-2104.

19. Bouhemad B, Mongodi S, Via G, Rouquette I. Ultrasound for "lung monitoring" of ventilated patients. Anesthesiology 2015;122(2):437-447.

20. Mongodi S, Bouhemad B, Orlando A, Stella A, Tavazzi G, Via G, et al. Modified lung ultrasound score for assessing and monitoring pulmonary aeration. Ultraschall Med 2017;38(5):530-537.

21. Mojoli F, Bouhemad B, Mongodi S, Lichtenstein D. Lung ultrasound for critically ill patients Authors. Am J Respir Crit Care Med 2019;199(6):701-714.

22. Mauri T, Yoshida T, Bellani G, Goligher EC, Carteaux G, Rittayamai $\mathrm{N}$, et al. Esophageal and transpulmonary pressure in the clinical setting: meaning, usefulness and perspectives. Intensive Care Med 2016;42(9):1360-1373.

23. Mojoli F, Iotti GA, Torriglia F, Pozzi M, Volta CA, Bianzina S, et al. In vivo calibration of esophageal pressure in the mechanically ventilated patient makes measurements reliable. Crit Care 2016;20:98.

24. Akoumianaki E, Maggiore SM, Valenza F, Bellani G, Jubran A, Loring $\mathrm{SH}$, et al. The application of esophageal pressure measurement in patients with respiratory failure. Am J Respir Crit Care Med 2014;189(5):520-531.

25. Lanteri CJ, Kano S, Sly PD. Validation of esophageal pressure occlusion test after paralysis. Pediatr Pulmonol 1994;17(1):56-62.

26. Higgs BD, Behrakis PK, Bevan DR, Milic Emili J. Measurement of pleural pressure with esophageal balloon in anesthetized humans. Anesthesiology 1983;59(4):340-343.

27. D’Angelo E, Robatto FM, Calderini E, Tavola M, Bono D, Torri G, Milic-Emili J. Pulmonary and chest wall mechanics in anesthetized paralyzed humans. J Appl Physiol 1991;70(6):2602-2610.

28. Baydur A, Behrakis PK, Zin WA, Jaeger M, Milic-Emili J. A simple method for assessing the validity of the esophageal balloon technique. Am Rev Respir Dis 1982;126(5):788-791.

29. Ball L, Pelosi P. Intraoperative mechanical ventilation in patients with non-injured lungs: time to talk about tailored protective ventilation?. Ann Transl Med 2016;4:4-6.

30. Güldner A, Kiss T, Serpa Neto A, Hemmes SNT, Canet J, Spieth PM, et al. Intraoperative protective mechanical ventilation for prevention of postoperative pulmonary complications. Anesthesiology 2015;123 (3):692-713.

31. O'Croinin D, Ni Chonghaile M, Higgins B, Laffey JG. Bench-to-bedside review: permissive hypercapnia. Crit Care 2005;9(1):51-59.

32. Yoshida T, Amato MBP, Grieco DL, Chen L, Lima CAS, Roldan R. Esophageal manometry and regional transpulmonary pressure in lung injury. Am J Respir Crit Care Med 2018;197:1018-1026.

33. Chiumello D, Cressoni M, Colombo A, Babini G, Brioni M, Crimella $\mathrm{F}$, et al. The assessment of transpulmonary pressure in mechanically ventilated ARDS patients. Intensive Care Med 2014;40(11):16701678.

34. Chiumello D, Coppola S, Froio S, Mietto C, Brazzi L, Carlesso E, Gattinoni L. Time to reach a new steady state after changes of positive end expiratory pressure. Intensive Care Med 2013;39(8):1377-1385.

35. Pereira SM, Tucci MR, Morais CCA, Simões CM, Tonelotto BFF, Pompeo MS, et al. Individual positive end-expiratory pressure settings optimize intraoperative mechanical ventilation and reduce postoperative atelectasis. Anesthesiology 2018:1-12.

36. Bergman NA, Tien YK. Contribution of the closure of pulmonary units to impaired oxygenation during anesthesia. Anesthesiology 1983;59(5):395-401.

37. Reber A, Nylund U, Hedenstierna G. Position and shape of the diaphragm: implications for atelectasis formation. Anaesthesia 1998;53 (11):1054-1061.

38. Loring SH, Behazin N, Novero A, Novack V, Jones SB, O'Donnell CR, Talmor DS. Respiratory mechanical effects of surgical pneumoperitoneum in humans. J Appl Physiol 2014;117(9):1074-1079.

39. Fahy BG, Barnas GM, Nagle SE, Flowers JL, Njoku MJ, Agarwal M. Effects of Trendelenburg and reverse Trendelenburg postures on lung and chest wall mechanics. J Clin Anesth 1996;8(3):236-244.

40. Lee HJ, Kim KS, Jeong JS, Shim JC, Cho ES. Optimal positive endexpiratory pressure during robot-assisted laparoscopic radical prostatectomy. Korean J Anesthesiol 2013;65(3):244-250.

41. Ladha K, Melo MFV, Mclean DJ, Wanderer JP, Grabitz SD, Kurth T, Eikermann M. Intraoperative protective mechanical ventilation and risk of postoperative respiratory complications: hospital based registry study. BMJ 2015;14:1-9.

42. Hickling KG. Best compliance during a decremental, but not incremental, positive end-expiratory pressure trial is related to open-lung positive end-expiratory pressure: a mathematical model of acute respiratory distress syndrome lungs. Am J Respir Crit Care Med 2001;163(1):69

43. Cavalcanti AB, Suzumura ÉA, Laranjeira LN, Paisani DM, Damiani LP, Guimarães HP, et al. Effect of lung recruitment and titrated positive end-expiratory pressure (PEEP) vs low PEEP on mortality in patients with acute respiratory distress syndrome: a randomized clinical trial. JAMA 2017;318(14):1335-1345.

44. Lai-Fook S, Rodarte J. Pleural pressure distribution and its relationship to lung volume and interstitial pressure. J Appl Physiol 1991;70(3): 967-978. 